\title{
The $11^{\text {th }}$ International Conference on Business Excellence
}

\author{
Strategy, Complexity and Energy in changing times
}

In the present challenging and competing environment with plenty of international academic conferences, The International Conference on Business Excellence (ICBE) held in Bucharest 3031st March 2017 is considered different and specific. Excellence is competition, differentiation and specificity.

Based on ten year experience, the main organizers representing the UNESCO Department for Business Administration, The Faculty of Business Administration in foreign languages and The Society of Business Excellence decided to use a different message, a different style, a different leadership and conference management. UNESCO Department for Business Administration as an UNESCO Chair is committed to promote long-life learning and education for sustainable development according to UNESCO objectives. Excellence is experience, imagination and creativity, team leadership and management performance.

The Conference was founded in 2006 by the Society of Business Excellence and represented one of the two important projects along with the international journal Management \& Marketing, Challenges for the Knowledge Society, indexed in various international databases including Scopus. Based on inspiration, but also strategic thinking, the founders of SBE tried to offer to future generations excellent tools for research, for collaboration, for networking and for internationalisation. Through commitment and performance, effort and passion, leadership and team spirit, the conference reached in 2017 the 11th edition. Excellence is vision, continuity and perseverance.

The history is full of scientific events, positive emotions, commitment and responsibility. First eight editions were strategically and emotionally connected with Transilvania University of Brasov, reflecting a strong partnership commitment for delivering excellence. Six conference volumes were indexed as web of science proceedings and the rest were published as special issues of international journals.

The 10th edition of the ICBE was dedicated to energy and environmental changes according to UNESCO objectives and mission. The mass-media partners appreciated the efforts and achievements of the organizing team in this very specialized field: The MBA in energy business and a conference with prestigious guest-speakers from academia, business environment and policy makers. The scientific output released: a special issue of journal MM dedicated to energy, climate change and sustainability indexed in Scopus database and the proceedings volume indexed in web of science. Excellence is research, commitment and prestige.

The 11th edition of International Conference on Business Excellence is the beginning of the new partnership between the academia, business and NGOs, revealing a rebranded and more dynamic dimension of their strong and long-term relationship. The institutional will, the team spirit and brain power have consolidated the partnership to excellence.

Strategy, Complexity and Energy in changing times - the theme of this year reflect a threedimensional perspective in a in a three-dimensional space characterized by uncertainty, complexity and dynamism. The motto of the conference reflects the spirit and the motivation for of the new team: The way to predict the future is to create it.

The structure of the conference with 8 minitracks and 3 workshops offered a complex framework where the triple helix specialists - university and research, consultancy and business, 
and policy making were able to create a stimulating environment for knowledge and knowhow business excellence transfers and alliance formation. These are the following: Energy, Climate Change and Sustainability; Challenges and Strategies in Business Education; Human Resources A Game Changer of the Business Strategy; International Business Finance in a Globalized World; Digitization of Business; Social Entrepreneurship for Local Change; Complexity; Business Models and Competitive Advantage for Technology Transfer Organizations; Sustainability in Tertiary Sector; Challenges for Developing Generic and Employability Skills for Global Business; International Perspectives on Future Developments.

The minitrack chairs of the sections and workshops consist in prestigious colleagues from various international universities (Romania, Italy, USA, Spain, Serbia). They offered not only their expertise in the selected topics, but also time and commitment to review and improve the scientific quality of the papers. Their professionalism and reputation have improved the qualitative standards of papers and the prestige of the conference. The 125 selected papers with blind review with the rejection rate of $43 \%$ proved the commitment to research quality and excellence.

The alliance portfolio of the conference was national and international focused, academic and business oriented. This to bridging the Romanian academic and business environment with the international environment by ensuring a better understanding of new challenges, opportunities and threats generated by globalization and competition fields like energy, complexity, social entrepreneurship, digitization, education, international business. In a changing and competitive environment, international dimension of the conference, the key for networking and further collaboration was strongly consolidated.

The 11th edition of the International Conference on Business Excellence has attracted the interest of more than 200 authors who submitted their scientific abstracts, out of which 125 were accepted for being presented at the conference, leading to a rejection rate of $43 \%$. The geographical distribution of the guest speakers, authors and members of the scientific committee covers the following countries: Bulgaria, France, Germany, Hungary, Iran, Italy, Mexico, Poland, Romania, Serbia, Singapore, Spain, Switzerland, The Netherlands, Turkey, UAE, and USA, and demonstrates the international collaboration.

The university partnership with Sapienza from Italy, Bucharest University, Politehnica University but also business partners have consolidated the partnership to excellence.

The scientific partnership with Management \& Marketing, Challenges for the Knowledge Society Journal, indexed in Scopus, Journal of Global Entrepreneurship Research indexed in Springer provided support for further publication of best papers selected. The main conference objective for the future is to consolidate the partnership with other prestigious journals indexed in web of science.

Scientific collaboration with De Gruyter publishing house offers the support for the conference proceedings indexation in web of science. The conference proceedings edited by Constantin Bratianu, Alina Mihaela Dima and Shahrazad Hadad is available online at the De Gruyter publishing house: https://www.degruyter.com/view/j/picbe. The past indexation in web of science of the six conference volumes including the last year conference proved the scientific quality of papers and reputation of International Committee. Based on scientific quality, excellence is also trust and confidence. 
Because excellence means also resources and support of business environment, the conference received also financial support and business sponsorship. Excellence is investment in quality and business education.

The project Triple Helix international cooperation in scientific research to support journals and conferences no 1367/16.11.2017 financed by the Romanian Ministry of Education in the 2016 national competition for special funds offered additional support for excellence in internationalization, reputation and prestige. This project created the opportunity to invite prestigious speakers from important universities: Constantin Bratianu, The Bucharest University of Economic Studies, Wolfgang Karl Härdle, Humboldt University Berlin, Michael Stoica, Washburn University School of Business, Marius STAN, Argonne National Laboratory and University of Chicago and Northwestern University. But also it provided financial support for conference proceedings publication and other indexations.

Another argument for excellence is reward and motivation. An international board with high expertise was appointed to select the best papers presented for final awards and their decision is the confidence in excellence evaluation. The Business Excellence Awards and the Best Paper Award of each section offered at the final ceremony reflect the commitment for the quality reward and performance evaluation.

International Business Excellence Conference is a useful tool for organising entities to identify new opportunities and capitalize on their learning. The 11th edition reflects a new vision, a new strategy, a new team, in a new and challenging environment.

Alina Mihaela Dima 